\title{
Tendências de pesquisas em ENPECs sobre questões sociocientíficas
}

Gisa Aparecida Dacorégio gisadacoregio@hotmail.com

orcid.org/0000-0003-3897-3142 Curitiba, Paraná, Brasil

João Amadeus Pereira Alves japalves@yahoo.com.br

Universidade Tecnológica Federal do

Paraná (UTFPR), Curitiba, Paraná, Brasil

\section{Leonir Lorenzetti}

leonirlorenzetti22@gmail.com

orcid.org/0000-0002-0208-2965

Universidade Federal do Paraná (UFPR),

Curitiba, Paraná, Brasil

\section{RESUMO}

O presente artigo busca traçar um recorte atual das tendências da produção científica sobre Questões Sociocientíficas a partir da análise dos trabalhos apresentados na forma de comunicação oral nas dez edições do Encontro Nacional de Pesquisa em Educação em Ciências, no período de 1997 a 2015. Utilizando a metodologia de pesquisa do Estado do Conhecimento, é realizado um mapeamento das pesquisas para identificar instituições por região do país, áreas de conteúdo, temáticas privilegiadas e referências de textos em português de autores brasileiros. Os resultados revelam que a produção ao longo desse período foi de 57 trabalhos publicados no evento. Esses textos estão enquadrados nas seguintes temáticas: Argumentação, Estado do Conhecimento, Estratégia Didática, Formação de Professores e Teórico. A área de Ensino em Ciências vem crescendo, tendo em vista o aumento do número de trabalhos aprovados nas edições do evento em questão, assim como de artigos enfocando Questões Sociocientíficas.

PALAVRAS-CHAVE: Ensino de Ciências. Estado do Conhecimento. Questões Sociocientíficas. 


\section{INTRODUÇÃO}

O ensino de Ciências com o enfoque Ciência, Tecnologia, Sociedade e Ambiente (CTSA) promove a educação de ciências e tecnologia, articulando suas implicações na sociedade e na natureza, para todos os cidadãos (PEREZ, 2012). De acordo com Fernandes e Pires (2013), a abordagem de conteúdos utilizando a perspectiva CTSA desenvolve os seguintes aspectos: o interesse do aluno pela ciência, o espírito crítico, o pensamento lógico e a tomada de decisão frente aos avanços científicos e tecnológicos.

A reflexão e a discussão de alunos e professores sobre questões que envolvam aspectos ambientais, políticos, econômicos, éticos, sociais e culturais podem ser desenvolvidas utilizando Questões Sociocientíficas (QSC). Tais questões possuem caráter controverso. São atuais, geralmente divulgadas pela mídia e também tratam de assuntos com o mesmo viés da Educação CTSA, ou seja, são relacionados a conhecimentos científicos e tecnológicos atrelados a sociedade e ambiente (PÉREZ, 2012).

Enquanto estratégia didática, a abordagem de QSC potencializa a participação dos alunos na aula e favorece a sua formação como cidadão crítico e atuante em sociedade. Nesse escopo, segundo Pérez (2012, p. 61), “o papel do professor é fundamental para orientar discussões com seus alunos sobre questões sociocientíficas para que eles se posicionem criticamente diante dessas questões, agindo racionalmente".

Dessa forma, este trabalho objetiva traçar um recorte atual das tendências da produção científica sobre QSC a partir da análise dos trabalhos apresentados na forma de comunicação oral nas dez edições do Encontro Nacional de Pesquisa em Educação em Ciências (ENPEC), no período de 1997 a 2015 - totalizando 10 edições, identificando nos artigos suas instituições por região do país, áreas de conteúdo, temáticas privilegiadas e referências de textos em português de autores brasileiros.

\section{MOVIMENTO CTS, EDUCAÇÃO CTSA E QUESTÕES SOCIOCIENTÍFICAS NO ENSINO DE CIÊNCIAS}

O movimento denominado Ciência, Tecnologia e Sociedade (CTS) surgiu em meados das décadas de 1960 e 1970, em um cenário de pós Segunda Guerra Mundial, e corroborou para o aumento das preocupações com os problemas ambientais resultados dos efeitos da ciência e tecnologia na sociedade e meio ambiente (AULER; BAZZO, 2001; SANTOS; MORTIMER, 2002; CUNHA, 2006; PINHEIRO; SILVEIRA; BAZZO, 2007; VAZ; FAGUNDES; PINHEIRO, 2009).

Um marco considerado histórico para o movimento CTS diz respeito à publicação de duas obras, em 1962: "Primavera Silenciosa" de Rachel Carson e "A Estruturas das Revoluções Científicas" de Thomas Kuhn. A primeira obra mencionada relata desastres ambientais causados pela contaminação de agrotóxicos, iniciando, assim, a reflexão da população para a conscientização ambiental e preocupação com a preservação de recursos naturais. O livro de Kuhn trata do conhecimento científico, em que é questionada a concepção de ciência da época, a qual era considerada tradicional, influenciando os rumos da filosofia da ciência. 
Apesar do movimento CTS não ter origem no campo educacional, os pressupostos desse enfoque estão recebendo cada vez mais adeptos da área da educação e, com isso, influenciam currículos da Educação Básica, Ensino Superior e Pós-Graduação (MOURA; SÁ; RABELO, 2015). Nessa conjuntura, "os trabalhos curriculares em CTS surgiram, assim, como decorrência da necessidade de formar o cidadão em ciência e tecnologia, o que não vinha sendo alcançado adequadamente pelo ensino convencional de ciências" (VAZ; FAGUNDES; PINHEIRO, 2009, p. 108).

Auler (2007, p. 1) defende a necessidade de profundas mudanças no campo curricular, de modo a contemplar configurações:

\footnotetext{
Mais abertas a temas, a problemas contemporâneos marcados pela componente científico-tecnológica, enfatizando-se a necessidade de superar configurações pautadas unicamente pela lógica interna das disciplinas, passando a serem configuradas a partir de temas/problemas sociais relevantes, cuja complexidade não é abarcável pelo viés unicamente disciplinar.
}

CTSA pode ser a terminologia encontrada em textos mais recentes, objetivando reforçar a importância do Ambiente (associado à letra " $A$ ") nesta perspectiva de educação em Ciências. Inicialmente, a sigla utilizada nos trabalhos de pesquisa era CTS, entretanto ao incorporar o enfoque CTS no Ensino de Ciências, a sigla CTSA é também utilizada, agregando a dimensão ambiental nas relações CTS, "devido à importância que tem o tratamento de problemas socioambientais" (PÉREZ; PEÑAL; VILLAMIL, 2007, p. 1, tradução nossa).

Pérez (2012) adota a denominação CTSA para se referir à abordagem contemporânea de CTS, sendo que a considera mais ampla por tratar também de problemas socioambientais diversos. Dessa forma, "a educação CTSA impõe novas referências de saberes e práticas integrando a tecnologia aos conteúdos, promovendo a sensibilização do educando, para que este construa uma nova consciência relativa aos impactos ambientais" (CAVALCANTI; COSTA; CHRISPINO, 2014, p. 35).

Entretanto, para Santos (2007), a vertente ambiental está contida na tríade CTS, apesar de que algumas discussões desse movimento podem não abordar ou priorizar as questões ambientais, então a educação CTSA resgata o papel da educação ambiental.

A ciência e tecnologia são abordadas de maneira tradicional nas salas de aula. E isso ocorre porque, geralmente, os professores não têm sido preparados para tratar de aspectos sociais, culturais, políticos, históricos e éticos, os quais fundamentam o enfoque CTSA na prática docente (PEREZ, 2012). O professor de Ciências deve ser um "profissional crítico comprometido com o estudo social da ciência, capaz de construir estratégias pedagógicas e didáticas alternativas que promovam nos estudantes a responsabilidade na tomada de decisões como futuros cidadãos" (PÉREZ; PEÑAL; VILLAMIL, 2007, p. 2, tradução nossa).

Nessa perspectiva, a utilização de Questões Sociocientíficas em aulas de Ciências pode propiciar de forma concreta a incorporação, pelo professor, dos pressupostos das relações CTSA em sua prática docente. Para Santos et al. (2011, p. 3), "a educação CTSA é essencial para que os estudantes desenvolvam um 
raciocínio ético que os permita refletir e agir de acordo com as necessidades dos debates de questões sociocientíficas em sala de aula".

Questões que, juntas, envolvem danos ambientais, decisões políticas, implicações econômicas e éticas, interesses sociais e culturais relativos à Ciência e Tecnologia, e que objetivam a formação de um cidadão crítico e atuante na sociedade são denominadas Socioscientific Issues, termo cunhado por Wessel (1980, apud FLEMING, 1986), que pode ser interpretado como QSC, Temas Controversos ou ainda Aspectos Sociocientíficos (ASC). QSC, Temas Controversos e ASC são tratados de formas diferentes, dependendo das considerações do autor que os aborda.

Segundo Reis (2004, p. 48), QSC têm "uma dimensão científica ou tecnológica considerável". De acordo com Silva e Santos $(2015$, p. 2), as QSC "são aquelas que apresentam dilemas sociais com ligações conceituais, processuais ou tecnológicas com a ciência".

Pérez (2012, p. 25) destaca que "as QSC abrangem controvérsias sobre assuntos sociais que estão relacionados com conhecimentos científicos de atualidade e, portanto, em termos gerais são abordados nos meios de comunicação de massa", a exemplo de internet, revistas, jornais, TV, rádio, entre outros.

Para Ratcliffe e Grace (2003, p. 2-3, tradução nossa) as QSC possuem as seguintes características:

\begin{abstract}
Tem base na ciência, e frequentemente se localizam na fronteira do conhecimento científico; envolvem a formação de opiniões, escolhas a nível pessoal ou social; são frequentemente relatadas pela mídia; possuem informações incompletas e conflitos de evidências científicas; possuem dimensões locais ou globais ligadas a estruturas políticas e sociais; podem envolver elementos de desenvolvimento sustentável; envolvem valores e raciocínio ético; podem requerer algum entendimento de probabilidade ou risco; e são tópicos frequentes na vida cotidiana.
\end{abstract}

Segundo Zuin e Freitas (2007), os temas controversos que abordam aspectos científicos e tecnológicos são compreendidos como situações sociocientíficas polêmicas. Esses temas controversos são distintos das problematizações geralmente tratadas em aulas de Ciências, pois:

\footnotetext{
As controvérsias socioambientais e sociocientíficas são pouco delimitadas, multidisciplinares, heurísticas, carregadas de valores (invocando, por exemplo, valores estéticos, ecológicos, morais, educacionais, culturais e religiosos) e marcadas pela ausência de conhecimento disciplinar disponível. Geralmente, o envolvimento neste tipo de problemas controversos conduz a diversas "soluções" alternativas, cada uma das quais com aspectos positivos e negativos (REIS, 2007, p. 129).
}

O termo ASC está relacionado a uma abordagem em perspectiva mais ampla, de forma temática ou mais pontual, com exemplificação contextualizada e frases interrogativas durante debates, por exemplo (SANTOS; MORTIMER, 2009). 


\section{PERCURSOS METODOLÓGICOS}

O presente estudo caracteriza-se como uma pesquisa de natureza qualiquantitativa e seu delineamento encaixa-se em uma pesquisa bibliográfica, a qual é desenvolvida a partir de material já elaborado - textos científicos -, e permite mapear uma faixa ampla de fenômenos (GIL, 1999). A pesquisa ainda se caracteriza como do tipo Estado do Conhecimento, tendo em vista que "aborda apenas um setor das publicações sobre o tema estudado" (ROMANOWSKI; ENS, 2006, p. 40).

A primeira fase da pesquisa consistiu em um levantamento dos trabalhos apresentados na forma de comunicação oral relacionados a Questões Sociocientíficas, localizados nas ATAS dos ENPECs disponíveis no site da Associação Brasileira de Pesquisa em Educação em Ciências - ABRAPEC (http://abrapecnet.org.br/wordpress/pb/atas-dos-enpecs/), envolvendo as dez edições do evento, no período compreendido entre 1997 a 2015. Os trabalhos foram selecionados a partir da presença dos termos "Sociocientíficos(as)" ou "Sócio-científicos(as)" em seus títulos, resumos ou palavras-chave.

Na segunda fase do trabalho, foi realizada a análise dos textos científicos identificados através da leitura do resumo e/ou do corpo de cada produção, assim como de suas referências. Alguns dados foram tabelados, como: título, instituições, áreas de conteúdo, temáticas privilegiadas e referências de textos em português de autores brasileiros.

\section{ENCONTRO NACIONAL DE PESQUISA EM EDUCAÇÃO EM CIÊNCIAS (ENPEC)}

Esse evento de periodicidade bianual, teve início no ano de 1997. Ele é organizado pela Associação Brasileira de Pesquisa em Educação em Ciências (ABRAPEC) em parceria com pesquisadores membro, bem como aglutina pesquisadores e professores principalmente das áreas de Educação em Ciências, Biologia, Física e Química. O Quadro 1 traz um breve histórico dessas 10 edições do ENPEC.

Quadro 1 - Histórico do ENPEC

\begin{tabular}{l|c|c|c} 
Ano & Edição & Local & Data \\
\hline 1997 & I & Águas de Lindóia - SP & 27 a 29 de novembro \\
\hline 1999 & II & Valinhos - SP & 1 a 4 de setembro \\
\hline 2001 & III & Atibaia - SP & 7 a 10 de novembro \\
\hline 2003 & IV & Bauru - SP & 25 a 29 de novembro \\
\hline 2005 & V & Bauru - SP & 28 de novembro a 3 de dezembro \\
\hline 2007 & VI & Florianópolis - SC & 26 de novembro a 2 de dezembro \\
\hline 2009 & VII & Florianópolis - SC & 8 a 13 de novembro \\
\hline 2011 & VIII & Campinas - SP & 5 a 9 de dezembro \\
\hline 2013 & IX & Águas de Lindóia - SP & 10 a 13 de novembro \\
\hline 2015 & X & Águas de Lindóia - SP & 24 a 27 de novembro
\end{tabular}

Fonte: Os autores (2017). 


\section{RESULTADOS E DISCUSSÕES}

De acordo com o levantamento de dados, o Quadro 2 mostra a distribuição de trabalhos no período de 1997 a 2015, especialmente aqueles envolvendo QSC.

Quadro 2 - Histórico da distribuição de trabalhos do ENPEC

\begin{tabular}{|c|c|c|c|c|c|c|c|c|c|c|c|}
\hline \multirow{2}{*}{$\begin{array}{c}\text { Número } \\
\text { de } \\
\text { Trabalhos }\end{array}$} & \multicolumn{11}{|c|}{ ENPEC } \\
\hline & $\mathbf{I}$ & II & III & IV & $\mathbf{V}$ & VI & VII & VIII & IX & $x$ & Total \\
\hline $\begin{array}{c}\text { Total do } \\
\text { ENPEC }\end{array}$ & 70 & 69 & 141 & 216 & 421 & 371 & 358 & 1152 & 943 & 1272 & 5013 \\
\hline $\begin{array}{c}\text { Analisados } \\
\text { nesta } \\
\text { pesquisa }\end{array}$ & 0 & 0 & 1 & 0 & 0 & 0 & 3 & 14 & 21 & 18 & 57 \\
\hline
\end{tabular}

Fonte: Adaptado de Lorenzetti, Silva e Bueno (2015).

Nas dez edições do ENPEC foram publicados em suas atas 5013 trabalhos. Destes, 57 trabalhos estão relacionados às QSC, O que corresponde a aproximadamente $1,1 \%$. O IX ENPEC é o evento que aparece com o maior número de trabalhos a serem analisados, sendo 2,2\% do número total daquele ano. Em seguida, aparece a décima edição, com $1,4 \%$ do total de trabalhos e a oitava, com aproximadamente $1,2 \%$.

Foram localizadas 34 Instituições de Ensino distintas nas quais os autores estavam ou ainda estão vinculados, entre elas cinco são universidades estrangeiras: duas da Inglaterra (University College London e University of Leeds), duas da Colômbia (Universidad Distrital Francisco José de Caldas e Universidad Pedagógica Nacional) e uma da Espanha (Universitat de Barcelona).

Entre as instituições brasileiras, a Universidade Estadual Paulista se destacou com 13 trabalhos (22,8\%), a Universidade de Brasília com 11 (19,3\%) e a Universidade de São Paulo com 10 (17,5\%). A maioria das universidades apresentou apenas um trabalho. Vale ressaltar que muitos trabalhos foram elaborados e submetidos em parcerias entre universidades, alguns de diferentes regiões do país.

Então, quando analisados por região, o Sudeste e Centro Oeste se destacam, nessa ordem, com relação ao número de trabalhos no evento: $66 \%$ e $22 \%$ dos trabalhos, respectivamente. Em seguida, a região Nordeste aparece com 7\%. Dois artigos tiveram autores de instituições do Norte e apenas um teve autor de uma universidade do Sul, conforme a Figura 1. 
Figura 1 - Gráfico da distribuição dos trabalhos por região

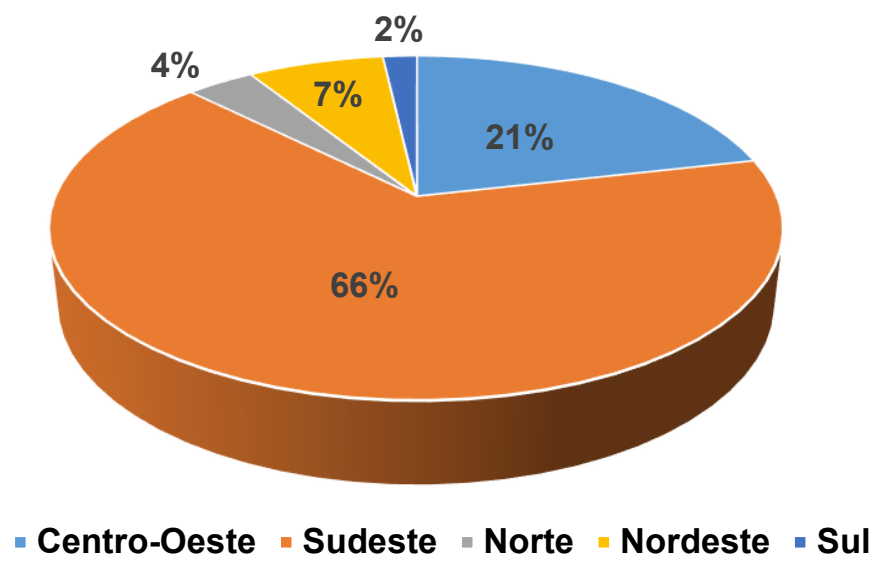

Fonte: Os autores (2017).

De acordo com a área de conteúdo predominante nos artigos analisados, foram elencadas quatro opções: Química, Física, Biologia e Ciências. Esta última engloba os trabalhos sem especificações relacionadas às demais alternativas e se destacou com metade dos trabalhos (50\%). A subárea da Química apareceu com o segundo maior número de trabalhos, sendo 14 (25\%), enquanto a Biologia teve listados nove trabalhos (16\%) e a Física teve cinco (9\%), conforme a Figura 2.

Figura 2 - Gráfico da distribuição de trabalhos por área de conteúdo

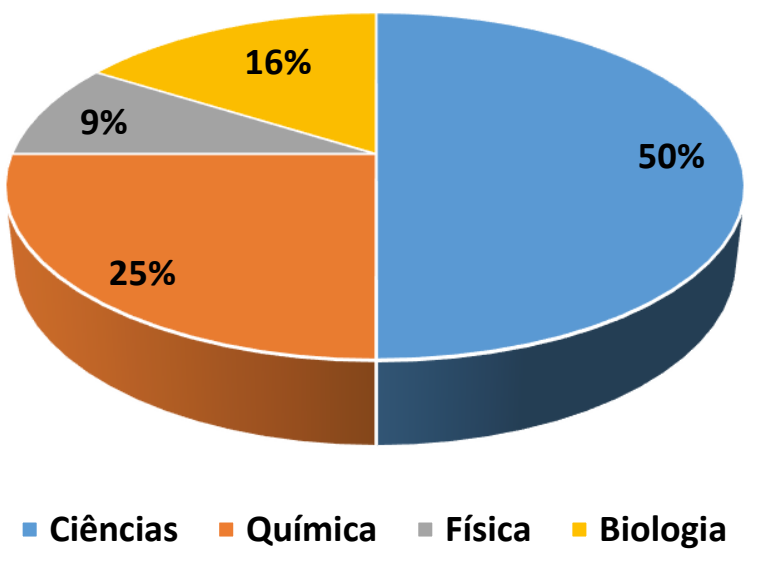

Fonte: Os autores (2017).

As pesquisas foram classificadas nas seguintes Temáticas: Argumentação, Estado do Conhecimento, Estratégia Didática, Formação de Professores e Teórico. Os textos da temática Argumentação analisam a interação discursiva, geralmente em salas de aula, provocadas por debates sobre QSC. A temática Estado do Conhecimento engloba trabalhos de mapeamento sobre QSC em diferentes épocas e materiais (revistas, eventos, teses e dissertações etc). Estratégia Didática diz respeito a unidades didáticas realizadas, normalmente em salas de aula de Ensino Médio, contendo atividades relacionadas a QSC em conjunto de conteúdos e temas, como por exemplo: nanotecnologia, recursos hídricos, reações químicas, agrotóxicos etc. Em Formação de Professores foram encontrados textos sobre o tratamento de QSC em licenciaturas. Por fim, a temática Teórico diz respeito a 
discussões sobre QSC sem práticas envolvidas, como a análise de documentos oficiais (sobre currículo e avaliação de questões do ENEM), descrição de ferramentas para constituição de dados, entre outros. Alguns trabalhos estavam relacionados a duas categorias ao mesmo tempo, entretanto esses foram incluídos no item mais focado durante o desenvolvimento do estudo, conforme Tabela 1.

Tabela 1 - Número de trabalhos por Temática

\begin{tabular}{ccc} 
Temática & Número de Trabalhos & Porcentagem (\%) \\
\hline Argumentação & 15 & 26,3 \\
\hline Estado do Conhecimento & 7 & 12,2 \\
\hline Estratégia Didática & 11 & 19,3 \\
\hline Formação de Professores & 12 & 21,1 \\
\hline Teórico & 12 & 21,1 \\
\hline
\end{tabular}

Fonte: Os autores (2017).

Observa-se que a Temática Argumentação se destaca com 26,3\% dos trabalhos relacionados nesse levantamento. Em seguida aparecem Formação de Professores e Teórico com 12 artigos cada (21,1\%). A categoria Estratégia Didática teve 11 textos. Enquanto Estado do Conhecimento teve sete trabalhos contemplados.

Como este estudo se trata também de um Estado do Conhecimento, cabe destacar os artigos elencados nessa categoria, relatando-os em forma de um simplificado resumo e em ordem cronológica - do mais antigo para o mais recente.

Santos e colaboradores (2011) investigaram as metodologias dos trabalhos de pesquisa em Ensino de Ciências sobre o tratamento de QSC no Ensino Médio. Para isso, foram selecionadas quatro dissertações da área e, então, emergiram quatro eixos de análise: entendimento dos argumentos; julgamento da posição dos especialistas; pesquisa na literatura e no campo; e participação democrática nas decisões.

Penha e Carvalho (2011) apresentaram um recorte de pesquisas de doutorado sobre a inserção de QSC no Ensino de Ciências. Após a apreciação dos estudos, emergiram as categorias de análise relacionadas aos benefícios individuais e coletivos desejáveis para o Ensino de Ciências. Sobre os benefícios individuais, foram listadas: entendimento, domínio, representação e utilização do conteúdo científico; entendimento dos aspectos da natureza da ciência; ampliação das habilidades intelectuais; utilização do conhecimento científico e técnico nas interações do cotidiano; entendimento das relações CTS; e tomada de decisões sobre questões sócio-técnica-científicas. As categorias sobre os benefícios coletivos utilizadas foram: desenvolvimento político, econômico e social; tomada de decisões públicas; apoio popular e público às ciências; proteção do meio ambiente; e qualidade de vida.

Silva e colaboradores (2013) identificaram pesquisas com enfoque na interface entre o Ensino de Ciências e a Educação Ambiental que adotassem temas controversos sociocientíficos no ensino. Foram utilizados os trabalhos publicados nos cinco primeiros anais do Encontro de Pesquisa em Educação Ambiental. A investigação resultou em somente um artigo, que abordou a temática controversa de acordo com os pressupostos esperados pelo trabalho. 
Lima e Martins (2013) apresentaram um levantamento da produção acadêmica no que tange a abordagem CTS e o uso de QSC no ensino de Ciências, no período de 2008 a 2013. Foram selecionadas oito revistas (quatro nacionais e quatro internacionais) da área para a realização dessa pesquisa. Basicamente, "no contexto nacional, as discussões CTS norteiam os currículos de ciências e os temas sociocientíficos são tratados como estratégias didático-pedagógicas para um ensino mais contextualizado e integrado; no contexto internacional, as discussões CTS são pano de fundo nas discussões de temas sociocientíficos" (LIMA; MARTINS, 2013, p. 1).

Kato e colaboradores (2013) analisaram trabalhos de ensino de Ciências, publicados nos ENPECs de 1997 a 2009, que contemplassem aspectos químicos, ambientais e temas controversos sociocientíficos. Foram encontradas cinco pesquisas que abordassem todos os temas propostos, uma do ano de $2005 \mathrm{e}$ quatro de 2009, ou seja, resultados distintos comparados a esta pesquisa decorrente da metodologia aplicada quanto às palavras-chave utilizadas. De acordo com estes autores, o contexto da abordagem de temáticas ambientais relacionado à realidade dos alunos é uma tendência.

Bezerra e Amaral (2015) identificaram tendências teóricas e metodológicas de artigos sobre temas sociocientíficos em periódicos nacionais do ensino de Ciências, entre 2005 e 2014. Foram elencados 14 estudos para análise, que demonstrou falta de definição dos termos empregados para controvérsias e suas versões, como QSC, ASC, temas controversos etc. Outro ponto destacado diz respeito aos principais referenciais teóricos utilizados, em que Wildson L. P. dos Santos e Eduardo F. Mortimer foram os autores mais referenciados.

Fernandes e colaboradores (2015) realizaram uma revisão da literatura do ensino de Ciências sobre QSC na perspectiva do Letramento Científico nos anos iniciais do Ensino Fundamental. A pesquisa foi realizada em quatro periódicos da área. Apenas um artigo foi identificado com relação às QSC.

Desses trabalhos elencados na categoria Estado do Conhecimento relatados, referentes à área de conteúdo, apenas o artigo de Kato e colaboradores (2013) foi listado, sendo atrelado ao ensino de Química. Todos os outros pertencem a Ciências, de um modo geral. Quanto às regiões do país, apenas a pesquisa de Bezerra e Amaral (2015) é do Nordeste, em que ambos os autores são vinculados à Universidade Federal Rural de Pernambuco, enquanto os outros foram elaborados por instituições do Sudeste.

Por fim, analisaram-se as Referências de cada pesquisa com o intuito de listar os textos em português, somente de autores brasileiros, mais utilizados como base para elaboração dos estudos. Os 57 trabalhos apontaram 29 referências distintas, conforme tabela 2.

Tabela 2 - Referências em português de autores brasileiros encontradas nos artigos analisados

\begin{tabular}{c|c|c|c}
\hline Autores & Título & Ano & $\begin{array}{c}\text { Número de vezes } \\
\text { referenciada }\end{array}$ \\
\hline $\begin{array}{c}\text { SANTOS, W. L. P.; } \\
\text { MORTIMER, E. F. }\end{array}$ & $\begin{array}{c}\text { Abordagem de aspectos } \\
\text { sociocientíficos em aulas de } \\
\text { ciências: possibilidades e limitações }\end{array}$ & 2009 & 12 \\
\hline LOPES, N. C. & $\begin{array}{c}\text { Aspectos formativos da experiência } \\
\text { com questões sociocientíficas no }\end{array}$ & 2010 & 6 \\
\hline
\end{tabular}




\begin{tabular}{|c|c|c|c|}
\hline Autores & Título & Ano & $\begin{array}{l}\text { Número de vezes } \\
\text { referenciada }\end{array}$ \\
\hline & $\begin{array}{c}\text { ensino de ciências sob uma } \\
\text { perspectiva crítica }\end{array}$ & & \\
\hline $\begin{array}{l}\text { SANTOS, W. L. P.; } \\
\text { MORTIMER, E. F. }\end{array}$ & $\begin{array}{c}\text { Tomada de decisão para ação } \\
\text { social responsável no ensino de } \\
\text { ciências }\end{array}$ & 2001 & 5 \\
\hline GUIMARÃES, M. A. & $\begin{array}{c}\text { Raciocínio informal e a discussão } \\
\text { de questões sociocientíficas: o } \\
\text { exemplo das células-tronco } \\
\text { humanas }\end{array}$ & 2011 & 4 \\
\hline PENHA. S. P. & $\begin{array}{l}\text { Atividades sociocientíficas em sala } \\
\text { de aula de física: as argumentações } \\
\text { dos estudantes }\end{array}$ & 2012 & 4 \\
\hline SANTOS, W. L. P. & $\begin{array}{c}\text { Aspectos sociocientíficos em aulas } \\
\text { de Química }\end{array}$ & 2002 & 4 \\
\hline $\begin{array}{l}\text { ZUIN, V. G; } \\
\text { FREITAS, D. }\end{array}$ & $\begin{array}{l}\text { A utilização de temas controversos: } \\
\text { estudo de caso na formação de } \\
\text { licenciandos numa abordagem } \\
\text { CTSA }\end{array}$ & 2007 & 4 \\
\hline $\begin{array}{l}\text { BARBOSA, L. G. } \\
\text { D'C; LIMA, M. E. C. } \\
\text { C. }\end{array}$ & $\begin{array}{l}\text { A abordagem de temas } \\
\text { controversos no ensino de ciências: } \\
\text { enfoques das pesquisas brasileiras } \\
\text { nos últimos anos }\end{array}$ & 2009 & 3 \\
\hline $\begin{array}{l}\text { BARBOSA, L. G. } \\
\text { D'C; LIMA, M. E. C. } \\
\text { C; MACHADO, A. } \\
\text { H. }\end{array}$ & $\begin{array}{l}\text { Controvérsias sobre o aquecimento } \\
\text { global: circulação de vozes e de } \\
\text { sentidos produzidos em sala de } \\
\text { aula }\end{array}$ & 2012 & 3 \\
\hline $\begin{array}{l}\text { MUNDIM, J. V.; } \\
\text { SANTOS, W. L. P. }\end{array}$ & $\begin{array}{l}\text { Ensino de ciências no ensino } \\
\text { fundamental por meio de temas } \\
\text { sociocientíficos: análise de uma } \\
\text { prática pedagógica com vista à } \\
\text { superação do ensino disciplinar }\end{array}$ & 2012 & 3 \\
\hline $\begin{array}{c}\text { SILVA, L.; } \\
\text { CARVALHO, L. M. }\end{array}$ & $\begin{array}{l}\text { A temática ambiental e o processo } \\
\text { educativo: o ensino de física a } \\
\text { partir de temas controversos }\end{array}$ & 2007 & 3 \\
\hline $\begin{array}{l}\text { MENDES, M. R. M.; } \\
\text { SANTOS, W. L. P. }\end{array}$ & $\begin{array}{c}\text { Argumentação em discussões } \\
\text { sociocientíficas. Investigações em } \\
\text { Ensino de Ciências }\end{array}$ & 2013 & 2 \\
\hline SANTOS, P. G. F. & $\begin{array}{l}\text { O tratamento de Questões } \\
\text { Sociocientíficas em um grupo de } \\
\text { professores e a natureza do } \\
\text { processo formativo fundamentado } \\
\text { em uma perspectiva crítica }\end{array}$ & 2013 & 2 \\
\hline $\begin{array}{l}\text { SILVA, O. B.; } \\
\text { OLIVEIRA, J. R. S.; } \\
\text { QUEIROZ, S. L. }\end{array}$ & $\begin{array}{c}\text { Abordagem CTS no ensino médio: } \\
\text { estudo de caso com enfoque } \\
\text { sociocientífico }\end{array}$ & 2011 & 2 \\
\hline $\begin{array}{l}\text { VIEIRA, K. R. C. F.; } \\
\text { BAZZO, W. A. }\end{array}$ & $\begin{array}{l}\text { Discussões acerca do aquecimento } \\
\text { global: uma proposta CTS para } \\
\text { abordar esse tema controverso em } \\
\text { sala de aula } \\
\end{array}$ & 2007 & 2 \\
\hline AZEVEDO, R. O. M. & $\begin{array}{c}\text { O enfoque CTS na formação de } \\
\text { professores de Ciências e a }\end{array}$ & 2013 & 1 \\
\hline
\end{tabular}




\begin{tabular}{|c|c|c|c|}
\hline Autores & Título & Ano & $\begin{array}{l}\text { Número de vezes } \\
\text { referenciada }\end{array}$ \\
\hline & $\begin{array}{c}\text { abordagem de questões } \\
\text { sociocientíficas }\end{array}$ & & \\
\hline BORTOLETTO, A. & $\begin{array}{c}\text { Formação Continuada de } \\
\text { Professores: A Experiência de uma } \\
\text { Temática Sociocientífica na } \\
\text { Perspectiva do Agir Comunicativo }\end{array}$ & 2013 & 1 \\
\hline BORTOLETTO, A. & $\begin{array}{c}\text { Temas sociocientíficos: análise de } \\
\text { processos argumentativos no } \\
\text { contexto escolar }\end{array}$ & 2009 & 1 \\
\hline $\begin{array}{l}\text { CARVALHO, L. M. } \\
\text { O.; CARVALHO, W. } \\
\text { L. P. }\end{array}$ & $\begin{array}{c}\text { Formação de Professores e } \\
\text { Questões Sociocientíficas no Ensino } \\
\text { de Ciências }\end{array}$ & 2003 & 1 \\
\hline $\begin{array}{l}\text { FELICIO, B. V. S.; } \\
\text { KATO, D. S.; SILVA, } \\
\text { D. K.; FRANCO, R. } \\
\text { A. G. }\end{array}$ & $\begin{array}{l}\text { Aspectos químicos, ambientais e } \\
\text { temas controversos presentes nas } \\
\text { pesquisas em ensino de ciências: } \\
\text { uma análise da produção dos } \\
\text { ENPEC }\end{array}$ & 2014 & 1 \\
\hline $\begin{array}{l}\text { GUIMARÃES, M. } \\
\text { A., CARVALHO, W. } \\
\text { L. P.; OLIVEIRA, M. } \\
\text { S. }\end{array}$ & $\begin{array}{l}\text { Raciocínio moral na tomada de } \\
\text { decisões em relação a questões } \\
\text { sociocientíficas: o exemplo do } \\
\text { melhoramento genético humano }\end{array}$ & 2010 & 1 \\
\hline $\begin{array}{l}\text { HOFFMANN, M. B.; } \\
\text { DUSO, I. }\end{array}$ & $\begin{array}{c}\text { Controvérsias sociocientíficas no } \\
\text { ensino de ciências: aspectos da } \\
\text { pesquisa brasileira publicada em } \\
\text { periódicos }\end{array}$ & 2012 & 1 \\
\hline LOPES, N. C. & $\begin{array}{l}\text { A constituição de associações livres } \\
\text { e o trabalho com as questões } \\
\text { sociocientíficas na formação de } \\
\text { professores }\end{array}$ & 2013 & 1 \\
\hline OLIVEIRA, W. M. & $\begin{array}{c}\text { Sistema de análise de discussões } \\
\text { sociocientíficas: Um estudo piloto } \\
\text { de duas estratégias didáticas } \\
\text { distintas }\end{array}$ & 2011 & 1 \\
\hline $\begin{array}{l}\text { RAMOS, M. B.; } \\
\text { SILVA, H. C. }\end{array}$ & $\begin{array}{l}\text { Para pensar as Controvérsias } \\
\text { Científicas em Aulas de Ciências }\end{array}$ & 2007 & 1 \\
\hline SÁ, L. P. & $\begin{array}{l}\text { Estudo de Casos na Promoção da } \\
\text { Argumentação sobre Questões } \\
\text { Sóciocientíficas no Ensino Superior } \\
\text { de Química }\end{array}$ & 2010 & 1 \\
\hline $\begin{array}{l}\text { SANTOS, M. S.; } \\
\text { AMARAL, C. L. C.; } \\
\text { MACIEL, M. L. }\end{array}$ & $\begin{array}{c}\text { Temas sociocientíficos “cachaça” } \\
\text { em aulas práticas de química na } \\
\text { educação profissional: uma } \\
\text { abordagem CTS }\end{array}$ & 2012 & 1 \\
\hline $\begin{array}{l}\text { SANTOS, W. L. P.; } \\
\text { MORTIMER, E. F. }\end{array}$ & $\begin{array}{l}\text { Aspectos sociocientíficos em aulas } \\
\text { de química e interações em sala de } \\
\text { aula }\end{array}$ & 2003 & 1 \\
\hline $\begin{array}{l}\text { SILVA, P. F.; } \\
\text { KRASILCHIK, M. }\end{array}$ & $\begin{array}{c}\text { Bioética e ensino de ciências: o } \\
\text { tratamento de temas controversos } \\
\text { - dificuldades apresentadas por } \\
\text { futuros professores de ciências e } \\
\text { de biologia }\end{array}$ & 2013 & 1 \\
\hline
\end{tabular}


Foram listados 39 autores brasileiros. Os textos de Wildson Luiz Pereira dos Santos foram os mais utilizados como referências dos artigos analisados, sendo o seu nome encontrado seis vezes na tabela 2. Em seguida, Eduardo Fleury Mortimer, um dos autores que publicou com o anterior - Santos, apareceu três vezes. Os resultados já apresentados quanto aos autores mais referenciados convergem com o trabalho de Bezerra e Amaral (2015). Nataly Carvalho Lopes, Márcio Andrei Guimarães, Luís Gustavo D’Carlos Barbosa, Maria Emília Caixeta de Castro Lima, Luiz Marcelo de Carvalho, Adriana Bortoletto e Washington Luiz Pacheco de Carvalho foram autores referenciados duas vezes. Todos os outros nomes foram listados apenas uma vez.

O texto mais referenciado (12 vezes) é "Abordagem de aspectos sociocientíficos em aulas de ciências: Possibilidades e limitações", de 2009, publicado na Revista Investigações em Ensino de Ciências e elaborado por Wildson Luiz Pereira dos Santos e Eduardo Fleury Mortimer. Esses autores possuem maior número de publicações sendo utilizadas como referência nos trabalhos analisados nesta investigação.

Nota-se que a referência mais antiga encontrada é do ano de 2001, caracterizando, assim, esse tipo de pesquisa como recente. Alguns artigos apresentaram referências apenas em língua inglesa ou espanhola, outros de autores colombianos, ingleses e portugueses, os quais não foram foco da análise. Sete trabalhos não apresentaram nenhuma referência base para as discussões de QSC.

\section{CONSIDERAÇÕES FINAIS}

Esta pesquisa analisou 57 artigos relacionados às Questões Sociocientíficas apresentados como comunicação oral nos ENPECs, no período de 1997 a 2015. Constatou-se que na oitava edição do evento houve um crescimento do número de trabalhos aprovados sobre o assunto em foco, esse número continuou em ascensão na nona edição e diminuiu um pouco no último ENPEC.

É nítido o crescimento da área de ensino em Ciências e do evento em questão, tendo em vista o aumento do número de trabalhos aprovados a cada ano. Os trabalhos enfocando QSC aparentemente estão aparecendo com maior força no evento, sendo interessante uma análise das próximas edições.

Evidencia-se a prevalência de trabalhos nas regiões Sudeste e Centro Oeste. 0 maior número de estudos está relacionado a Ciências de uma forma geral. Observa-se que a Temática Argumentação é a mais apresentada, a qual possui grande relação com as QSC que podem ser abordadas em discussões e debates.

Dessa forma, uma possibilidade que vem ganhando espaço diz respeito à inserção dessas discussões envolvendo as QSC, sendo que possuem objetivos comuns à perspectiva CTSA, como focar em processos de formação para cidadania relacionados à sociedade atual (PEREZ, 2012).

Foram mencionados 29 textos em português, somente de autores brasileiros, totalizando em 39 nomes distintos, utilizados como base para elaboração da fundamentação sobre QSC. Wildson Luiz Pereira dos Santos é o autor que possui mais textos utilizados como referência para elaboração dos artigos analisados. Além disso, um artigo seu em conjunto com Eduardo Fleury Mortimer foi o mais 
referenciado. Todos eles foram publicados após o ano de 2000, indicando a recente pesquisa sobre o tema no país.

Por fim, defende-se a abordagem de QSC nas aulas da Educação Básica, Ensino Superior e Pós-Graduação na perspectiva CTSA, assim como a continuação de pesquisas da área com viés teórico-prático, a fim de encontrar cada vez mais opções de estratégias de ensino que auxiliem na renovação do ensino de Ciências. 


\title{
Research trends about socioscientific issues at ENPEC
}

\begin{abstract}
The purpose of this paper is to make a current cut of the trends on scientific production about socioscientific issues from the analysis of the papers presented in the modality of oral communication in the ten editions of the National Meeting of Research in Science Education (Encontro Nacional de Pesquisa em Educação em Ciências - ENPEC) on a period from 1997 to 2015. As a methodology this article used the "State of Knowledge", which is used to map researches and to identify institutions through regions of the country, content areas, main thematic areas and text references in Portuguese from Brazilian authors. The results revealed that the production through this period was of 57 papers published at the event. The papers were inserted on the following thematic: Argument, State of Knowledge, Didactic Strategy, Teacher Training and theoretical. The area of science education has been growing, according to the increase of approved papers in the editions of the aforementioned event, as well as articles focusing on socioscientific issues.

KEYWORDS: Science Education. State of Knowledge. Socioscientific issues.
\end{abstract}




\section{REFERÊNCIAS}

AULER, D.; BAZZO, W. A. Reflexões para a implementação do movimento CTS no contexto educacional brasileiro. Ciência \& Educação, v.7, n.1, p.1-13, 2001.

AULER, D. Enfoque Ciência-Tecnologia-Sociedade: Pressupostos para o contexto brasileiro. Ciências \& Ensino, v. 1, n. especial, p. 1-16, 2007.

BEZERRA, B. H. S.; AMARAL, E. M. R. Abordagem de temas sociocientíficos em periódicos nacionais de Ensino de Ciências publicados no período de 2005-2014. In: ENCONTRO NACIONAL DE PESQUISA EM EDUCAÇÃO EM CIÊNCIAS, X., 2015. Águas de Lindóia. Anais... Águas de Lindóia, 2015.

CAVALCANTI, D. B.; COSTA, M. A. F.; CHRISPINO, A. Educação Ambiental e Movimento CTS, caminhos para a contextualização do Ensino de Biologia. Revista Práxis, v. 6, n. 12, p. 27-42, 2014.

CUNHA, M. B. O movimento Ciência/Tecnologia/Sociedade (CTS) e o ensino de ciências: condicionantes estruturais. Varia Scientia, v. 6, n. 12, p. 121-134, 2006.

FERNANDES, I. M. G.; PIRES, D. M. As inter-relações CTSA nos manuais escolares de ciências do 2을. EEB. EDUSER: revista de educação, v. 5, n. 2, p. 35-47, 2013.

FERNANDES, L. L.; SILVA, E. G.; CORDEIRO, E. L. S.; PRATA, R. V. O trabalho com Questões Sócio-científicas nas Séries Iniciais: uma revisão da literatura em Ensino de Ciências. In: ENCONTRO NACIONAL DE PESQUISA EM EDUCAÇÃO EM CIÊNCIAS, X., 2015. Águas de Lindóia. Anais... Águas de Lindóia, 2015.

FLEMING, R. Adolescent reasoning in socio-scientific issues, part I: Social cognition. Journal of Research in Science Teaching, v. 23, n. 8, p. 677-687, 1986.

GIL, A. C. Métodos e técnicas de pesquisa social. 5 ed. São Paulo: Atlas, 1999.

KATO, D. S.; FELICIO, B. V. S.; SILVA, D. K.; FRANCO, R. A. G. Aspectos químicos, ambientais e temas controversos presentes nas pesquisas em ensino de ciências: uma análise da produção dos ENPEC. In: ENCONTRO NACIONAL DE PESQUISA EM EDUCAÇÃO EM CIÊNCIAS, IX., 2013. Águas de Lindóia. Anais... Águas de Lindóia, 2013.

LIMA, A.; MARTINS, I. As interfaces entre a abordagem CTS e as questões 
NACIONAL DE PESQUISA EM EDUCAÇÃO EM CIÊNCIAS, IX., 2013. Águas de Lindóia. Anais... Águas de Lindóia, 2013.

LORENZETTI, L.; SILVA, T. F.; BUENO, T. N. N. A Pesquisa em Ensino de Química nos ENPECS (1997 a 2013): mapeando tendências. In: ENCONTRO NACIONAL DE PESQUISA EM EDUCAÇÃO EM CIÊNCIAS, X., 2015. Águas de Lindóia. Anais... Águas de Lindóia, 2015.

MOURA, G. T.; SÁ, R. A.; J. B. RABELO. O ensino de CTSA numa perspectiva de educação crítica. In: CONGRESSO NACIONAL DE EDUCAÇÃO, II., 2015. Campina Grande. Anais... Campina Grande, 2015.

PENHA, S. P.; CARVALHO, A. M. P. A inserção de aspectos sociais da ciência e da tecnologia no Ensino de Ciências: identificação de convergências internacionais. In: ENCONTRO NACIONAL DE PESQUISA EM EDUCAÇÃO EM CIÊNCIAS, VIII., 2011. Campinas. Anais... Campinas, 2011.

PEREZ, L. F. M. Questões sociocientíficas na prática docente: ideologia, autonomia e formação de professores. 1 ed. São Paulo: Editora Unesp, 2012.

PEREZ, L. F. M.; PEÑAL, D. C.; VILLAMIL, Y. M. Relaciones ciencia, tecnología, sociedad y ambiente a partir de casos simulados: una experiencia en la enseñanza de la química. Ciências \& Ensino, v. 1, n. especial, p. 1-16, 2007.

PINHEIRO, N. A. M.; SILVEIRA, R. M. C. F.; BAZZO, W. A. Ciência, tecnologia e sociedade: a relevância do enfoque CTS para o contexto do ensino médio. Ciência \& Educação, v. 13, n. 1, p. 71-84, 2007.

RATCLIFFE M.; GRACE M. Science education for citizenship: teaching socioscientific issues. Maidenhead: Open University Press, 2003.

REIS, P. G. R. Controvérsias sócio-científicas: discutir ou não discutir? 2004. 488 f. Tese (Doutorado em Educação) - Faculdade de Ciências da Universidade de Lisboa. Lisboa, 2004.

. Os Temas Controversos na Educação Ambiental. Pesquisa em Educação Ambiental, v. 2, n. 1, p. 125-140, 2007.

ROMANOWSKI, J. P.; ENS, R. T. As pesquisas denominadas do tipo "Estado da Arte" em educação. Revista Diálogo Educacional, v. 6, n. 19, p. 37-50, 2006. 
SANTOS, P. G. F.; LOPES, N. C.; CARNIO, M. P.; CARVALHO, L. M. O.; CARVALHO, W. L. P. A abordagem de questões sociocientíficas no ensino de ciências: uma compreensão das sequências didáticas propostas por pesquisas na área. In: ENCONTRO NACIONAL DE PESQUISA EM EDUCAÇÃO EM CIÊNCIAS, VIII., 2011. Campinas. Anais... Campinas, 2011.

SANTOS, W. L. P. Contextualização no ensino de ciências por meio de temas CTS em uma perspectiva crítica. Ciência \& Ensino, v. 1, n. especial, p. 1-12, 2007.

SANTOS, W. L. P.; MORTIMER, E. F. Abordagem de aspectos sociocientíficos em aulas de Ciências: Possibilidades e limitações. Investigações em Ensino de Ciências, v. 14, n. 2, p. 191-218, 2009.

. Uma análise de pressupostos teóricos da abordagem C-T-S (CiênciaTecnologia-Sociedade) no contexto da educação brasileira. Ensaio: Pesquisa em Educação em Ciências, v. 2, n. 2, p. 1-23, 2002.

SILVA, D. K.; KATO, D. S.; FRANCO, R. A. G.; SCHNEIDER, B. V. S. Os estudos sobre os temas controversos sociocientíficos nas pesquisas: a relação entre Educação Ambiental e o Ensino de Ciências no Encontro de Pesquisa em Educação Ambiental (EPEA). In: ENCONTRO NACIONAL DE PESQUISA EM EDUCAÇÃO EM CIÊNCIAS, IX., 2013. Águas de Lindóia. Anais... Águas de Lindóia, 2013.

SILVA, K. M. A.; SANTOS, W. L. P. Natureza epistêmica das Questões Sociocientíficas: uma análise a partir do pensamento complexo. In: ENCONTRO NACIONAL DE PESQUISA EM EDUCAÇÃO EM CIÊNCIAS, X., 2015. Águas de Lindóia. Anais... Águas de Lindóia, 2015.

VAZ, C. R.; FAGUNDES, A. B.; PINHEIRO, N. A. M. O Surgimento da Ciência, Tecnologia e Sociedade (CTS) na Educação: Uma Revisão. In: SIMPÓsıO NACIONAL DE ENSINO DE CIÊNCIA E TECNOLOGIA, I., 2009. Ponta Grossa. Anais... Ponta Grossa, 2009.

ZUIN, V. G.; FREITAS, D. A utilização de temas controversos: estudo de caso na formação de licenciandos numa abordagem CTSA. Ciências \& Ensino, v. 1, n. 2, p. 1-9, 2007. 
Recebido: 28 jul. 2017

Aprovado: 15 dez. 2017

DOI: $10.3895 /$ actio.v2n3.6803

Como citar:

DACORÉGIO, G. A.; ALVES, J. A. P.; LORENZETTI, L. Tendências de pesquisas em ENPECs sobre questões sociocientíficas. ACTIO, Curitiba, v. 2, n. 3, p. 79-96, out./dez. 2017. Disponível em:

$<$ https://periodicos.utfpr.edu.br/actio>. Acesso em: XXX.

Correspondência:

Gisa Aparecida Dacorégio

Rua Antonio Bridi, 136, Bonsucesso, Guarapuava, Paraná, Brasil.

Direito autoral: Este artigo está licenciado sob os termos da Licença Creative Commons-Atribuição 4.0

Internacional.

(c) (1) 